\title{
SAFETY AND THE ECONOMIC AND FINANCIAL PERFORMANCE IN THE AIRLINE INDUSTRY: IS THERE ANY RELATIONSHIP?
}

\author{
Nicole KALEMBA (D) ${ }^{{ }^{*}}$, Fernando CAMPA-PLANAS (D) ${ }^{2}$ \\ ${ }^{1}$ Universitat Oberta de Catalunya, Avinguda del Tibidabo 39-43, 08035, Barcelona, Spain \\ ${ }^{2}$ Universitat Rovira i Virgili, Avinguda de la Universitat, 1 43204, Reus, Spain
}

Received 29 January 2019; accepted 15 March 2019

\begin{abstract}
Safety has always been and is a key management aspect in the airline industry. Airline companies, airport management, aviation staff and air traffic control perform the impossible to ensure the lowest possible number of accidents and incidents for minimizing the number of fatalities.

The main objective of this paper is first, to determine and analyze literature published concerning safety in the airline business and, second, to see the relationship between safety and other related economic and financial indicators. The sample used is a collection of international airlines included in the JACDEC safety index, considering longitudinal data for the years 2011-2015.

The results revealed a non-significant effect for safety on the profitability of the airline companies, whereas a significant effect of safety on airlines' revenues was shown.
\end{abstract}

Keywords: safety management, airline companies, profitability, key performance indicators, JACDEC.

\section{Introduction and objectives}

Within the wide variety of factors and circumstances that affect the air transportation sector, one of the key elements is providing operations with a high standard of safety and efficiency to the passengers (International Civil Aviation Organization [ICAO], 2015), guaranteeing the safety of the persons that are operating around the aircraft, and the protection of the aircraft itself (AERTEC, 2013). Likewise, security plays an important role, especially after events as $9 / 11$. Security measures have been enhanced and improved drastically, increasing consequently the confidence of passengers, as well as their safety (Blalock, Kadiyali, \& Simon, 2007).

Air transport and in particular commercial airlines, stand out from other alternative means of transport. Characteristics as comfort, speed, cost, efficiency and flexibility (Air Transport Action Group, 2014; Kelemen, 2003), in addition to its much higher safety conditions as rail or road transport (Miller, Douglass, \& Pindus, 1994; Pacheco, Fernandes, \& Domingos, 2014; Vasigh, Tacker, \& Fleming, 2013; World Health Organization, 2015; ICAO, 2015) make it peculiar.

Figure 1 shows the relationship between the evolution of the number of passengers that has continually increased, and the number of fatal accidents that has significantly decreased in recent years.

According to the EASA Annual Safety Review (2015), in 2014, the number of fatal accidents was below the total average for the last 10 years (2004-2013), although 2014 was a year that stands out for its remarkable number of fatalities $(\mathrm{n}=904)$, due to two singular accidents. First, the flight MH370 of the Malaysian Airlines that crashed

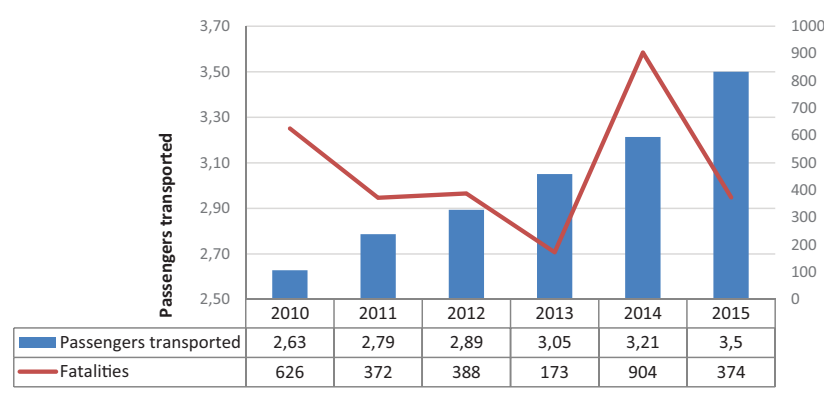

Figure 1. Number of fatal accidents and number of passengers 2010-2015 (source: created by the authors based on data of the World Bank, 2015 and ICAO, 2015)

*Corresponding author. E-mail: nkalemba@uoc.edu 
in the Southern Ocean (239 fatalities), and second, the flight MH17 by the same company in July 2014, that is still under investigation, having been most likely a victim of a terrorist attack while flying over Ukraine (298 fatalities) (Kalemba \& Campa-Planas, 2017).

Safety and its standards have always been one of the biggest priorities of the airline sector, playing an indispensable role in the day by day of the airlines. Its improvement has become a topic of growing interest in the operations management field (Liou, Yen, \& Tzeng, 2008; McFadden \& Hosmane, 2001), considering the main goal of the airline sector that is to guarantee the future viability of the airlines, reducing constantly the number of accidents and incidents (Shappell et al., 2007; Liao, 2015). Obviously, one of the explanatory components that contributed to the improvement of safety issues were the continuous changes in technology of aircraft and engines (Dionne, Gagné, Gagnon, \& Vanasse, 1997; Oster Jr., Strong, \& Zorn, 2013). In addition, initiatives undertaken by the governments and the airline industry made possible the improvement of airline safety operations during the last decades, through supporting regulation systems and the investigation of accident causes in the airline industry (Stolzer \& Goglia, 2015).

Especially since the deregulation act in 1978, airline companies had to deal with the increased pressure and competitiveness. This led initially to the reduction of investments in safety related issues for reducing costs (Moses \& Savage, 1990; Talley, 1992; Rhoades \& Waguespack Jr, 1999). Consequently, the fear was that those conditions would affect negatively the safety procedures and at the same time generate a decrease of profits inciting the airlines to scrimp and save on maintenance related matters (Morrison \& Winston, 1995).

Nevertheless, and although safety in the airline sector has generally become a topic of high interest, only few authors have investigated, especially in recent years, the impact of safety issues on the airlines' profitability (Golbe, 1986; Rose, 1990; Dionne et al., 1997; Raghavan \& Rhoades, 2005; Madsen, 2013; Oster et al., 2013). Due to this fact and having found the gap of very low attention of empirical research in the reviewed literature about the relationship of safety and performance, especially at the European level, the main objective of this paper is set: To determine and analyze the influence of safety on profitability, as well as of safety on the volume of revenues of the airline companies, considering furthermore other airline related influential factors and variables.

The paper is structured as follows. Initially, a conceptual framework and literature review is given. Section 2 describes the established research hypotheses. Section 3 gives information about the methodology applied for carrying out this study, while Section 4 introduces the reader to and interprets the estimation results. Finally, the last section gives an overview on the concluding remarks, key findings, and possible research limitations and suggestions for future research lines.

\section{Theoretical framework and literature review}

\subsection{Safety definitions and measurement}

Since there exist a multitude of approaches to safety, and in most cases literature about aviation safety is focused on engineering and technology (Oster et al., 2013), Kalemba and Campa-Planas (2017) outlined in their study, based on a safety related systematic literature review, that in most of the cases, safety is put into relation with terms as safety management, aircraft accidents and incidents.

Safety has always been an important matter and has improved especially since the era of the deregulation act in 1978 in the United States (De Jager, 1993). Thus, fatality rates have decreased (Dempsey \& Goetz, 1992) and air safety is much higher nowadays than before deregulation; consequence of aspects as the competition between airlines, air traffic and airport controls (Kahn, 2002), as well as the improved technology and advances in system infrastructures (Raghavan \& Rhoades, 2005).

The definition of safety in the airline industry consists in the number of accidents (Rose, 1990; Raghavan \& Rhoades, 2005). However, Rose (1990) highlights also aspects as the level of maintenance expenditure, operating procedures and the training of employees.

Furthermore, the International Civil Aviation Organization (ICAO, 2001; Huang, 2009) defines safety as a situation where the possibility of harm or loss of persons or properties is reduced and maintained at a low level through a continuous analysis of risks and hazard identification.

AERTEC (2013) contemplates three criteria for the definition of safety. To evaluate and detect risks to keep them at an acceptable low level; to inquire incidents for being proactive and making preventive and accurate decisions and, finally, to define safety levels and its correspondent indicators and variables for the measurement and follow-up of the safety level.

Thus, there are basically three aspects that are considered for the safety measurement: Accidents, incidents and operational problems. The ICAO (2011) examines accident rates as a primary indicator of total safety in the global air transport sector. Although safety is a "good business" (Madsen, 2013), literature (Amalberti, 2001; Lofquist, 2010) points out that measuring safety is a very complex process as mostly only accident rates are used as a proxy of measurement (Rose, 1990; Roelen \& Klompstra, 2012; Liou, Tzeng, \& Chang, 2007; Oster et al., 2013). Those are related to everything that has to do with aircraft accidents, collisions, events that cause deaths or serious incidents of persons and where the aircraft receives essential damage. Incident rates are only used as an alternative of measuring safety performance (Rose, 1990).

This excessive focus on accidents makes it certainly difficult to determine if an airline company is safe or not, as in these cases neither any weighting of the cause of accident is included nor any other criteria is considered. Obviously, the fact that, in general exists a very high safety level 
in the air transportation industry, and consequently a low number of incidents and accidents occur (Lofquist, 2010), makes it so complicated to measure safety as an objective and measurable indicator, as well as the problem that each organization defines and reports safety differently (Vasigh et al., 2013).

Additionally, Rose (1990), for instance, states that the direct driver of safety performance is the airlines' input into safety related activities. Maintenance that should be scheduled more frequently for reducing the probability of failures. The implementation of training programs to make sure the decrease of human failures, and, more advanced technology for improving safety over time.

Concluding, there exist especially two main problems related to the question how to measure safety. First, how is it possible to add up the number of accidents and incidents? Second, the lack of transparency of the maintenance expenditures by the airlines makes it difficult to get an insight into that aspect. On the one hand, because the airline companies itself do not offer data and, on the other hand, because the maintenance costs are included in the wet lease agreement, making it difficult to disassemble the expenditures in the companies that use this kind of fleet policy.

Beside the difficultness of how to measure safety, the number of existing indexes in the air transportation business is very scanty. Basically, there are two publicly available indexes, namely the JACDEC safety index and the Airline Ratings system (Airline Ratings, 2014).

In this study, we will make exclusively use of the JACDEC safety index, being the only publicly available index that considers different elements that are weighted and aggregated into one final number. This database, standing for Jet Airliner Crash Data Evaluation Center and developed by Jan-Arwed Richter and Christian Wolf, provides an overview of the following three main sections (Richter, 2014):

- Hull loss accidents: When an aircraft is damaged beyond economical repair or completely missed.

- Serious incidents: High probability of an accident (ICAO, 2014).

- Significant incidents: Being on the brink of a serious incident.

The JACDEC index rating started in 2003, records both, total losses and serious incidents, although according to Richter (2014), obviously, a total loss counts much more related to the results than a serious incident. The available data between the years 2011-2015 have been rated in different ways, as the index and its calculation formula were gradually influenced by different criteria during the years on the search for official and valid safety calculation resources on a global level; therefore, the results for the 5 years have been standardized and data is therefore comparable.

The index establishes a yearly overall ranking of those 60 airlines worldwide with the best results and shows the relationship between the accident rate and the flight performance of an airline. Furthermore, it considers about
1,000 flight operators and includes the last 30 years of total losses and significant accidents. For the calculation of the index, eight weighted and aggregated elements play a significant role (JACDEC, 2014):

- Annual Revenue Passengers Kilometers (RPKs): Cumulative RPKs are used.

- Fatalities: Total number of fatalities.

- Number of Total Losses: Refers to the before mentioned hull loss accidents.

- Number of Serious Incidents: Event where an accident has narrowly been avoided.

- Accident-Free Years: Refers to the number of years without hull losses; the more accident free years an airline has, the better will be the result of the index.

- IOSA Membership: Refers to the IATA Operational Safety Audit, included in 2005, although this calculation has a very low impact of weight.

- The Time Factor: In 2010 it has been included an "exponential moving average", therefore, the longer ago the accident has occurred, the lower will be the impact on the index.

- Country Transparency: Factor introduced in 2013 including 3 levels of country transparency; level 1 with the highest transparency of information statements, level 3 with the lowest transparency.

In conclusion, if an airline persists during the established period without any aircraft loss or incident, and considering the before mentioned aspects, an airline company would reach the optimum value of 0.000 . According to Richter (2014) it is currently the tool that best represents the so complex matter safety and therefore we decided to use the index for this study. Especially, in this highly specialized environment, where safety does not arise only from the reliable technology, and considering that it must be developed, lived and respected consistently (Just, 2014), it is a big challenge to obtain a dependable safety index.

\subsection{Relationship between safety and profitability}

Another approach of this study has been the safety-profitability link in the airline business. Two studies published by Madsen (2013) and Oster et al. (2013), already carried out literature reviews about what has been said in relation to the safety-profitability link in the airline industry.

However, the absolute value of literature existing on this topic is very scanty and obsolete, referring to the 1990s. The authors include three different possibilities of relationships.

Possibility 1: Safety is positively linked to profitability in the airline industry.

Rose (1990) examined a positive relationship between safety and profitability.

Possibility 2: Safety is negatively linked to profitability in the airline industry.

Contrary to this, Dionne et al. (1997), Raghavan and Rhoades (2005) showed results with a negative safetyprofitability link, being in both studies stronger in the case of smaller airlines. 
Possibility 3: There does not exist any relationship between safety and profitability in the airline industry.

Golbe (1986) analyzed and demonstrated the nonrelationship or statistical non-significance between both concepts, neither positive nor negative.

In general, only few studies (Golbe, 1986; Rose, 1990; Dionne et al., 1997); Raghavan and Rhoades (2005; Madsen, 2013; Oster et al., 2013) have addressed the effect that safety can have on profitability in the air transportation sector. In all of them, accidents rates have been used as a proxy for the safety concept. Furthermore, the exclusive use of only US carriers in the literature shows an existent gap, and therefore, this study uses airline companies at a global level.

\section{Research hypotheses}

Different hypotheses were proposed to answer the research questions of this paper, according to the established approaches and objectives and the reviewed literature (see Figure 2).

Hypothesis 1. Airline safety affects positively the profitability of airline companies.

As previously mentioned, several authors have already studied the effect of airline safety on the profitability of airlines, nevertheless there is not any clear statement and opinions are deeply divided on this issue and the way of measuring safety.

Our hypothesis agrees with Rose (1990) who demonstrated that safety is positively linked with profitability in the airline industry. Literature on this issue is obsolete and limited.

Hypothesis 2. Airline safety affects positively the revenues of airline companies.

It does not exist any literature based on this issue. Our hypothesis is that safety can positively influence the revenues of airline companies.

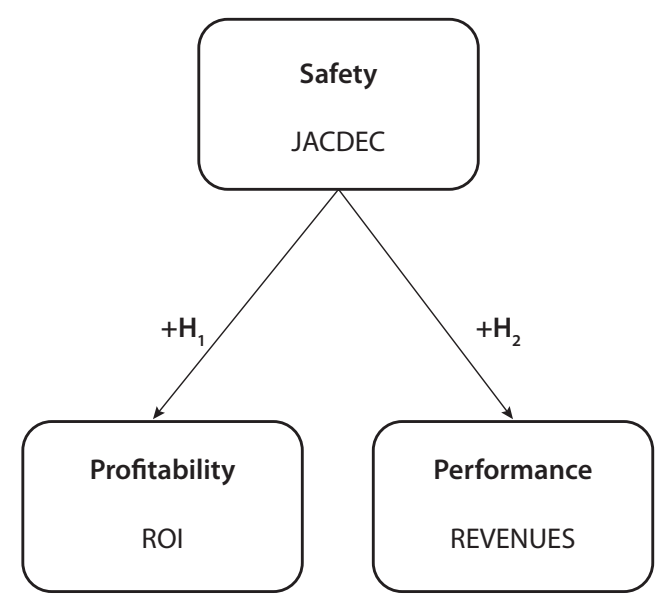

Figure 2. Conceptual model established through hypotheses (source: created by the authors)

\section{Methodology}

\subsection{Sources of information}

Different typologies of sources of information have been used. First, for the JACDEC safety index, it has been used secondary publicly available data from the safety own web page, as well as the German aviation magazine Aero International that offers once a year the final ranking of the 60 airlines with the best safety related results.

Second, for the financial data and operating metrics of the airline companies, source data were taken from the Thomson Reuters Eikon (2016) database, enabling to reflect therefore a 5-year time series. Eikon offers a real-time market data and was launched in 2010.

\subsection{Sample collection}

For both sources, we considered longitudinal time-series data from 2011 to 2015 . The hypotheses developed previously were tested on a sample of international airline companies where only those airlines, where the JACDEC index was available at least for 4 out of 5 years, were considered. The final unit of analysis included in the study was $n=45$ airlines.

Although the sample of 45 airlines could seem to be small, they represent in terms of total revenues more than the $70 \%$ over the total revenues of commercial airlines worldwide in 2016 (IATA, 2014, 2015).

\subsection{Measurement of variables and model description}

The established statistical models include three different types of variables; dependent, independent and control variables.

- Dependent variables: The purpose of this study was to examine the influence of safety on profitability and revenues of the airline companies. Financial ratios are fundamental for analyzing the financial statement and used to determine the profitability of the companies (Stepanyan, 2014). They are a key factor of contribution to the survival of the airlines (Oum \& Yu, 1998).

Therefore, this study includes in the first model as main dependent variable ROI, being the acronym of Return On Investment that refers to the performance of an investment and calculated through the quotient between the earnings before interest and taxes (EBIT) and the total assets of the company. Another possibility would be to include the ROE (Return on Equity), taking therefore into consideration the financial structure of the company. As we are analyzing the operational performance, ROI covers much better our objective of measuring exclusively business performance (Jacobson, 1987). The second model includes REVENUES used as dependent variables for performance measures. 
- Independent variable: Both models include as independent variable safety (JACDEC index - see explanation point 2.1.).

- Control variable: We introduced in both cases as control variable the logarithmic number of passengers, logPAX, being the number of passengers carried by the companies. This essential KPI in the airline industry is also important for the representation of others, as the Revenue per Passenger that represents the average income per passenger, as well as the Revenue Passenger Kilometer or yield (RPK) that stands for each flown kilometer, paid by each passenger. For the robustness check we will consider the variable FLEET, being the number of planes per Airline Company.

A panel data methodology with an over time series of longitudinal data has been used during the estimation process. The established model gives the possibility to observe a multitude of individuals over a period; specifically, it allows including both fixed and random effects.

The introduction of random effects admits considering unobserved heterogeneity of individuals, represented through the constant variable $\beta_{0 \mathrm{i}}$.

\section{Results}

All statistical analyses were carried out through the program R, version 3.3.3 ( $\mathrm{R}$ Development Core Team R, 2016), for providing results to the formulated research questions at the beginning. Tables 1 and 2 provide descriptive statistics and the correlation matrix, respectively, considering the variables used in this study.
It can be observed that the correlation between safety (JACDEC) and the other variables, besides the load factor, is not very high. In addition, important to mention the positive average of the ROI, fact that means that during the considered period of time the profitability of the airline companies has been beneficial.

As Table 2 shows, the correlation between size variables PAX, ASK and FLEET is very high, reason that has led us consequently to take the decision of using only one size variable in each of the established specification models. This allows avoiding any multicollinearity between the independent variables.

The analysis has been built on 2 models, determining the influence of safety on the profitability of the airline companies (model 1) and on the airlines' revenues (2).

The specifications for the models used, are as follows:

Model 1:

$\mathrm{ROI}_{\mathrm{it}}=\beta_{0 \mathrm{i}}+\beta_{11}$ JACDEC $_{\mathrm{it}-1}+\beta_{12}$ Load Factor $_{\text {it }}+$ $\beta_{13}$ SIZE $_{\text {it }}+\varepsilon_{\text {it }}$.

Model 2:

REVENUES $_{\text {it }}=\beta_{0 \mathrm{i}}+\beta_{21}$ JACDEC $_{\text {it- } 1}+\beta_{22}$ Load Factor $_{\text {it }}$ $+\beta_{23}$ SIZE $_{\text {it }}+\varepsilon_{\text {it }}$.

A panel data methodology has been used during the estimation process. In order to respond to our proposed hypotheses, we decided to run two regressions, one for each of the dependent variables, ROI and REVENUES, respectively. It is important to mention that we made use of the JACDEC index it-1, as we guess that a positive safety performance has an outcome on the profitability or revenues of an airline at least one year later.

Table 1. Descriptive statistics

\begin{tabular}{|l|c|c|c|c|}
\hline \multicolumn{1}{|c|}{ Variables } & Min & Max & Mean & Sd \\
\hline JACDEC & 0.005 & 1.298 & 0.175 & 0.268 \\
\hline PAX & 5.30 & 144.57 & 44.60 & 81.746 \\
\hline ASK & 4,245 & 427,532 & 107,830 & 0.049 \\
\hline LF & 0.658 & 0.926 & 0.796 & 244.712 \\
\hline FLEET & 39 & 1,549 & 276.2 & 0.066 \\
\hline ROI & -0.226 & 0.195 & 0.028 & 7.778 \\
\hline REVENUES & 2.12 & 36.95 & 9.11 & \\
\hline
\end{tabular}

Table 2. Correlation matrix

\begin{tabular}{|l|c|c|c|c|c|c|c|}
\hline \multicolumn{1}{|c|}{ Variables } & JACDEC & PAX & ASK & LF & FLEET & ROI & REVENUES \\
\hline JACDEC & 1 & & & & & & \\
\hline PAX & -0.120 & 1 & & & & & \\
\hline ASK & -0.165 & 0.704 & 1 & & & & \\
\hline LF & -0.420 & 0.181 & 0.053 & 1 & & & \\
\hline FLEET & -0.160 & 0.816 & 0.779 & 0.224 & 1 & & \\
\hline ROI & -0.130 & 0.194 & 0.074 & 0.183 & 0.105 & 1 & \\
\hline REVENUES & -0.217 & 0.728 & 0.765 & 0.121 & 0.791 & 0.132 & 1 \\
\hline
\end{tabular}


Statistics for models 1 and 2 (Table 3) show a significant and at the same time positive effect of size on both, ROI and REVENUES, measured through the logarithmic number of passengers $(\log \mathrm{PAX})(\beta=0.022 ; \mathrm{p}<0.01$ and $\beta=7.216 ; \mathrm{p}<0.001$, respectively).

Additionally, there does not exist any significant effect of safety on profitability (ROI) of the airline companies, fact that matches with the results given by Golbe (1986) who demonstrated in her study that there does not exist any relationship or statistical significance between both concepts, neither positive nor negative.

Therefore, the established hypothesis $\mathrm{H} 1$ is not supported $(\beta=-0.023 ; \mathrm{p}>0.05)$.

While safety does not have any significant effect on the airlines' ROI, it does so on the airlines' revenues, therefore hypothesis $\mathrm{H} 2$ is supported $(\beta=-5.456$; $\mathrm{p}<0.01)$.

Furthermore, Hausman and $\mathrm{F}$ tests have been conducted to determine the choice between pooling, fixed or random effects models.

Afterwards, robustness checks have been carried out to confirm whether our findings in relation to the effect of safety on the profitability and performance of the airlines are robust to alternative specifications of the established models. Results are reported in Table 4, where the size variable $\log \mathrm{PAX}$ is substituted by FLEET as a size variable.
No significant effect is seen of safety on profitability $(\beta=-1.004 \mathrm{e}-02 ; \mathrm{p}>0.05)$, therefore the rejection of our hypothesis $\mathrm{H} 1$ can be confirmed.

On the other hand, the robustness check of model 2 confirms the significant effect of safety on REVENUES $(\beta=-4.146 ; \mathrm{p}<0.05)$, as well as of size on REVENUES, measured through the variable FLEET $(\beta=0.026$; $\mathrm{p}<$ $0.001)$.

\section{Conclusions}

Since the Airline Deregulation Act of 1978, safety in the commercial airline industry has become of high interest for the public and policy makers, being a highly discussed topic (Rose, 1992; Kahn, 2002). As safety is a key element in the air transportation sector, and at the same time a very complex matter, the industry faces to a multitude of challenges that are necessary to consider for being able to maintain their level of safety, being essential for the future growth of the companies and the global economy.

Economically, there can be hard-hitting consequences to the airline companies, as each accident or incident can have negative influences on the passengers, and therefore, due to the reduction in demand, revenues of the airline industry decrease (Blalock et al., 2007). Thus, it is an essential feature for

Table 3. Estimation models 1 and 2

\begin{tabular}{|c|c|c|c|c|}
\hline & \multicolumn{2}{|c|}{ Model 1} & \multicolumn{2}{|c|}{ Model 2} \\
\hline \multirow[t]{2}{*}{ Variables } & \multicolumn{2}{|c|}{ Dependent variable: ROI } & \multicolumn{2}{|c|}{ Dependent variable: REVENUES } \\
\hline & $\beta$ & $\tau$ & $\beta$ & $\tau$ \\
\hline Intercept & $-0.494^{\star *}$ & -3.013 & $-107.747^{\star \star \star}$ & -8.439 \\
\hline JACDEC $_{\text {it-1 }}$ & -0.023 & -0.936 & $-5.456^{\star \star}$ & -2.870 \\
\hline Load factor $_{\text {it }}$ & 0.169 & 1.304 & -9.198 & -0.910 \\
\hline Size $(\log P A X)_{\text {it }}$ & $0.022^{\star *}$ & 2.842 & $7.216^{\star * *}$ & 11.803 \\
\hline Hausman test & \multicolumn{2}{|c|}{4.167} & \multicolumn{2}{|c|}{1.935} \\
\hline Adjusted $\mathrm{R}^{2}$ & \multicolumn{2}{|c|}{0.073} & \multicolumn{2}{|c|}{0.517} \\
\hline $\mathrm{F}$ & \multicolumn{2}{|c|}{$4.719^{\star *}$} & \multicolumn{2}{|c|}{$51.238^{\star * *}$} \\
\hline
\end{tabular}

Note: Beta weights and t-values are given. ${ }^{* *} \mathrm{p}<0.001$; ${ }^{* *} \mathrm{p}<0.01$; ${ }^{*} \mathrm{p}<0.05$.

Table 4. Estimation models 1 and 2: Robustness check

\begin{tabular}{|c|c|c|c|c|}
\hline & \multicolumn{2}{|c|}{ Robustness check Model 1} & \multicolumn{2}{|c|}{ Robustness check Model 2} \\
\hline \multirow[t]{2}{*}{ Variables } & \multicolumn{2}{|c|}{ Dependent variable: ROI } & \multicolumn{2}{|c|}{ Dependent variable: REVENUES } \\
\hline & $\beta$ & $\tau$ & $\beta$ & $\tau$ \\
\hline Intercept & $-2.177 e-01$ & -1.819 & $-17.326^{*}$ & 2.191 \\
\hline $\mathrm{JACDEC}_{\mathrm{it}-1}$ & $-1.004 \mathrm{e}-02$ & -0.377 & $-4.146^{\star}$ & -2.356 \\
\hline Load factor $_{\text {it }}$ & $2.949 \mathrm{e}-01$ & 1.988 & -17.946 & -1.832 \\
\hline Size $(\text { FLEET) })_{\text {it }}$ & $3.133 \mathrm{e}-05$ & 1.285 & $0.026^{\star * \star}$ & 15.944 \\
\hline Hausman test & \multicolumn{2}{|c|}{2.673} & \multicolumn{2}{|c|}{$29.779^{* * *}$} \\
\hline Adjusted $\mathrm{R}^{2}$ & \multicolumn{2}{|c|}{0.044} & \multicolumn{2}{|c|}{0.664} \\
\hline $\mathrm{F}$ & \multicolumn{2}{|c|}{$3.095^{\star}$} & \multicolumn{2}{|c|}{$91.340^{\star * *}$} \\
\hline
\end{tabular}


each airline company to offer high safety standards to ensure the health of the airline customers and citizens.

However, after decades of significant safety improvements, it is verified that passenger fatalities have decreased significantly during the last decades, while the number of passengers has increased constantly (World Bank, 2015; ICAO, 2015). Even so, recent airline accidents show that there remain vulnerabilities that have to be improved.

The paper shows that the literature reviewed about safety in the airline business undergoes a meaningful gap. Only a few number of papers exist in relation to the effect that safety has on airline management and its results. In relation to current research, there do not exist any recent papers that consider the influence of safety on the profitability or performance of the airlines.

Therefore, this study examined the interplay and outcomes between different factors, as safety, size, profitability and performance of airlines.

For the development of this study, the JACDEC safety index, as well as the operating metrics of each of the airlines and financial key performance indicators were used, considering the 2011-2015 period.

The provided results show a significant effect of both, size and safety on airlines' revenues; while a non-significant effect is given by safety on the airlines' profitability.

\section{Potential limitations in the study}

This study has some limitations to consider. As stated previously, there are some restrictions that make it so complex to find the right way of measuring airline safety and therefore to obtain a result of the true safety performance of airline companies. This is a general restriction for any study related to the measurement of safety in the airline industry, as airline safety rankings are highly criticized. Skytrax (2016) for example, being a reference regarding airline and airport reviews, states that they do not make any use of a comparative safety rating. They suggest that there is not any correct way of measuring safety for giving reliable information to the passengers. As we could see, the JACDEC index shows a lack of information, as it is not $100 \%$ clear in its web how the index is built up. Even so, the JACDEC safety index is the index that nowadays better represents the safety matter (Richter, 2014), and there does not exist any other safety index that could offer publicly and homogenous available information.

Another limitation in this study is the restriction to a certain number of airline companies and the period considered, due to the restraint of data available. Furthermore, this study included only airline companies that are ranked among the top 60 in relation to their level of safety, fact that makes it difficult to offer a higher sample rate and therefore a better statistical outcome.

\section{Further research}

Altogether and despite the mentioned limitations, this article provides an insight for managerial implications as well as for the operations of airline companies. Managers, considering the operations of airline companies, should especially give importance to a proactive safety management. This could therefore allow the managers a better decision-making process, contemplating a risk management strategy and considering necessary actions that can reduce safety risks.

Nevertheless, there are still some lines of enquiry that could be established for future research.

Firstly, it would be highly recommendable to have access to a greater sample of data for offering a much more representative sample as well as consequently to include other essential KPIs related to the airline industry, as for instance the types and age of aircrafts, pilots and their workload, maintenance or training costs or operating procedures, between others.

Secondly, it could be very interesting, when analyzing safety and its possible influences on profitability and revenues, to distinguish between the safety level of the different types of airlines, as small and medium size carriers, as well as to take into consideration the difference between Low Cost and Full Cost Carriers.

Likewise, considering that safety is one of the top priorities of the airline companies additionally to the quality that should be offered to the customers, it would be interesting to study the safety-quality link. Both concepts are indispensables in the context of the airline industry. Therefore, it could be useful to see the interrelationship between both elements.

Finally, for further research lines aspects as overflown countries and number of operations by airports could be considered at the same time as putting more focus into cabin safety related issues and terms as human factors.

\section{References}

AERTEC. (2013). Seguridad aeroportuaria: safety \& security. Retrieved June 25, 2017 from https://www.aertecsolutions.com

Airline Ratings. (2014). Retrieved March 2, 2017 from https:// www.airlineratings.com

Air Transport Action Group. (2014). Retrieved March 14, 2017 from https://www.atag.org

Amalberti, R. (2001). The paradoxes of almost totally safe transportation systems. Safety Science, 37, 109-126. https://doi.org/10.1016/S0925-7535(00)00045-X

Arhall, J., \& Cox, E. (2013). Key performance indicators for SAS flights. Linköping University.

De Jager, W. C. (1993). The effects of airline deregulation on airline safety: an econometric analysis (Doctoral dissertation). Retrieved from https://pdxscholar.library.pdx.edu/cgi/viewcontent.cgi? article=2296\&context=open_access_etds

Dempsey, P. S., \& Goetz, A. R. (1992). Airline deregulation and laissez-faire mythology. Westport, CT: Quorum Books.

Dionne, G., Gagné, R., Gagnon, F., \& Vanasse, C. (1997). Debt, moral hazard and airline safety. An empirical evidence. Journal of Econometrics, 79, 379-402.

EASA Annual Safety Review 2014. (2015). European aviation safety agency, 2015. Retrieved from https://www.easa.europa. eu/newsroom-and-events/news/annual-safety-review-2014

Golbe, D. (1986). Safety and profits in the airline industry. The Journal of Industrial Economics, 34(3), 305-318. https://doi.org/10.2307/2098573 
Huang, J. (2009). Aviation safety and ICAO. Universiteit Leiden. International Air Transport Association. (2014, 2015). Retrieved June 21, 2017 from https://www.iata.org

International Civil Aviation Organization. (2001). Determination of a definition of aviation safety (Working paper No. ANWP/7699). Retrieved from https://www.icao.int

International Civil Aviation Organization. (2011). Situación de la seguridad operacional de la aviación mundial (Information Paper). Retrieved from https://www.icao.int/safety/Documents/ICAO_State-of-Global-Safety_web_SP.pdf

International Civil Aviation Organization. (2014). Second highlevel safety conference 2015 (HLSC 2015) planning for global aviation safety improvement (Information Paper). Retrieved from https://www.icao.int/Meetings/HLSC2015/Documents/ WP/wp102_rev_en.pdf

International Civil Aviation Organization. (2015). Safety report 2015 edition. Retrieved from https://www.icao.int/safety/ documents/icao_safety_report_2015_web.pdf

JACDEC. (2014). Retrieved June 24, 2017 from https://www. jacdec.de

Jacobson, R. (1987). The validity of ROI as a measure of business performance. The American Economic Review, 77(3), 470-478.

Just, O. (2014). Vorwort. In J. A. Richter \& C. Wolf (Eds.), Mayday, feuer an bord. Schwarze tage der Luftfahrt. GeraMond.

Kahn, A. (2002). Airline deregulation. In The Concise Encyclopedia of Economics. Library Economics Liberty. Retrieved January 15, 2017 https://www.econlib.org

Kalemba, N., \& Campa-Planas, F. (2017). Safety as a management concept in the air transport sector: A systematic literature review. Intangible Capital, 13(1), 71-93.

https://doi.org/10.3926/ic.918

Kelemen, Z. (2003). Latest information technology development in the airline industry. Periodica Polytechnica Transportation Engineering, 31(1-2), 45-52.

Liao, M. Y. (2015). Safety Culture in commercial aviation: Differences in perspective between Chinese and Western pilots. Safety Science, 79, 193-205. https://doi.org/10.1016/j.ssci.2015.05.011

Liou, J. J. H., Tzeng, G. H., \& Chang, H. C. (2007). Airline safety measurement using a hybrid model. Journal of Air Transport Management, 13, 243-249.

https://doi.org/10.1016/j.jairtraman.2007.04.008

Liou, J. J. H., Yen, L., \& Tzeng, G. H. (2008). Building an effective safety management system for airlines. Journal of Air Transport Management, 14(1), 20-26.

https://doi.org/10.1016/j.jairtraman.2007.10.002

Lofquist, E. A. (2010). The art of measuring nothing: The paradox of measuring safety in a changing civil aviation industry using traditional safety metrics. Safety Science, 48(10), 15201529. https://doi.org/10.1016/j.ssci.2010.05.006

Madsen, P. M. (2013). Perils and profits: A reexamination of the link between profitability and safety in U.S. Aviation. Journal of Management, 39(3), 763-791.

https://doi.org/10.1177/0149206310396374

McFadden, K. L., \& Hosmane, B. S. (2001). Operations safety: an assessment of a commercial aviation safety program. Journal of Operations Management, 19, 579-591.

https://doi.org/10.1016/S0272-6963(01)00062-6

Miller, T., Douglass, J., \& Pindus, N. (1994). Road injury: Causes, costs, and comparisons with other transport modes. Journal of Safety Research, 25(4), 183-195.

https://doi.org/10.1016/0022-4375(94)90043-4

Morrison, S. A., \& Winston, C. (1995). The evolution of the airline industry. The Bookings Institution, Washington D.C.
Moses, L. N., \& Savage, I. (1990). Aviation deregulation and safety: theory and evidence. Journal of Transport Economics and Policy, 24, 171-188.

Oster Jr., C. V., Strong, J. S., \& Zorn, C. K. (2013). Analyzing aviation safety: Problems, challenges, opportunities. Research in Transportation Economics, 43, 148-164.

https://doi.org/10.1016/j.retrec.2012.12.001

Oum, T. H., \& Yu, C. (1998). An analysis of profitability of the world's major airlines. Journal of Air Transport Management, 4, 229-237. https://doi.org/10.1016/S0969-6997(98)00023-4

Pacheco, R. R., Fernandes, E., \& Domingos, E. M. (2014). Airport airside safety index. Journal of Air Transport Management, 34, 86-92. https://doi.org/10.1016/j.jairtraman.2013.08.007

Raghavan, S., \& Rhoades, D. L. (2005). Revisiting the relationship between profitability and air carrier safety in the US airline industry. Journal of Air Transport Management, 11, 283290. https://doi.org/10.1016/j.jairtraman.2005.01.003

R Development Core Team R. (2016). A language and environment for statistical computing. Vienna, Austria: R Foundation for Statistical Computing. Retrieved from https://www.Rproject-org

Rhoades, D. L., \& Waguespack Jr, B. (1999). Better safe than service? The relationship between service and safety quality in the US airline industry. Managing Service Quality, 9(6), 396400. https://doi.org/10.1108/09604529910304143

Richter, J. A. (2014). The JACDEC data base. User guide explanations and definitions. JACDEC Gbr.

Roelen, A. L. C., \& Klompstra, M. B. (2012). The challenges in defining aviation safety performance indicators. Paper presented at the PSAM 11 \& ESREL 2012, 25-29 June 2012. Helsinki, Finland.

Rose, N. L. (1990). Profitability and product quality: Economic determinants of airline safety performance. Journal of Political Economy, 98, 944-964. https://doi.org/10.1086/261714

Rose, N. L. (1992). Fear of flying? Economic analysis of airline safety. Journal of Economic Perspectives, 6(2), 75-94. https://doi.org/10.1257/jep.6.2.75

Shappell, S., Detwiler, C., Holcomb, K., Hackworth, C., Boquet, A., \& Wiegmann, D. A. (2007). Human error and commercial aviation accidents: an analysis using the human factors analysis and classification system. Human Factors, 49(2), 227-242. https://doi.org/10.1518/001872007X312469

Skytrax. (2016). Retrieved February 22, 2017 from https://www. airlinequality.com

Stepanyan, A. (2014). Traditional ratio analysis in the airline business: a case study of leading U.S carriers. International Journal of Advances in Management and Economics, 3(2), 175-189.

Stolzer, A. J., \& Goglia, J. J. (2015). Safety management systems in aviation (2nd ed.). Ashgate.

Talley, W. K. (1992). The impact of deregulation on airline safety: profit-safety and market-response arguments. Paper presented at the International Conference Series on Competition and Ownership in Land Passenger Transport. Retrieved from https://hdl.handle.net/2123/12193

Thomson Reuters. (2016). Eikon database. Retrieved from https:// www.customers.thomsonreuters.com/eikon/?

Vasigh, B., Tacker, T., \& Fleming, K. (2013). Introduction to air transport economics: from theory to applications. Burlington, VT: Ashgate.

World Bank. (2015). Retrieved March 21, 2017 from https:// www.datos.bancomundial.org

World Health Organization. (2015). Global status report on road safety. WHO. 